\title{
Experience of a quality assessment scheme for non-laboratory glucose meters
}

\author{
T R Trinick, E Duly
}

\begin{abstract}
In late 1989 a quality assessment scheme was introduced for glucose meters at 12 non-laboratory sites in a unit of management. The overall monthly imprecision of the meters varied from $3.4 \%$ to $17 \cdot 1 \%$, the highest coefficients of variation being recorded for glucose concentrations outside the range 3-20 $\mathrm{mmol} / 1$. In the same period $37 \%$ of results fell outside $\pm 10 \%$ of laboratory set target limits; $13 \%$ fell outside $\pm 20 \%$ of these limits. Participants have been advised of the unreliability of results outside the range 3-20 mmol/1. The main benefit of the scheme has been the improved confidence of users in the results obtained.
\end{abstract}

Testing outside laboratories has increased recently; further increases can be expected with the publication of guidelines for pharmacists aiming to set up a variety of analytical services. ${ }^{1}$ In particular, blood glucose meters are in widespread use. Serious concern has been expressed about the accuracy and safety of glucose monitoring by non-laboratory personnel, ${ }^{23}$ and recent guidelines on nonlaboratory testing have been produced by the Association of Clinical Biochemists (ACB). The major recommendations are: that equipment should be acquired only with the agreement of the head of the appropriate laboratory department; that users should receive proper training in the use of equipment; use quality control procedures; document results; and that responsibility must be clearly assigned for the various aspects of the use of such equipment.

In our unit there are 12 glucose meters in use (two casualty departments, two coronary care units, two outpatient departments, a medical investigation unit, three medical wards, one intensive care unit and one health centre). In 1989 we set up a scheme along the lines of the ACB recommendations, and in this report we review our experience after a year.

\section{Methods}

We used only one make of glucose meter and after reviewing published reports chose the Boehringer Reflolux II. ${ }^{5}$ Two members of staff from each meter site were selected to attend a training session run by the laboratory. The format of the training session consisted of an initial explanation on the correct use of the meter by the manufacturer followed by an introduction to the concepts of quality control, examination of areas of responsibility, and discussion about health and safety matters by a member of the laboratory staff. Each participant in the scheme was issued with a copy of guidelines which included clear instructions on the type of quality control material available, when they should be used and the recording of quality control and patient results. Only staff who completed a training session were eligible to use the meters.

Internal quality control material (Reflolux II control, Boehringer Mannheim; 90727) with mean glucose concentrations (acceptable ranges) of $2.4(1.6-3.2) \mathrm{mmol} / \mathrm{l}$ and 16.1 (13.7-18.4) $\mathrm{mmol} / 1$ were provided for each site. These controls are run with each test or group of tests and gave an indication of the precision obtained by the operator. If control readings fell outside the ranges stated users were asked to recalibrate and clean the instrument, and if still unsuccessful to contact the laboratory. Each month an external quality control solution of glucose was also prepared by the laboratory and dispensed to all sites. This control gives an indication of the accuracy obtained by the operator. On the basis of results returned by the participants a monthly report, coded for confidentiality, was issued to each site. This provided information on how their results compared with the laboratory result and with each other's.

\section{Results}

Records of the internal quality control scheme, after the exclusion of results falling outside the acceptable range, show that for the high control coefficients of variation (CVs) 
Precision of non-laboratory Reflolux II meters using glucose solutions in aqueous benzoic acid as controls

\begin{tabular}{lccc}
\hline Month & $\begin{array}{l}\text { Number of } \\
\text { estimations }\end{array}$ & $\begin{array}{c}\text { Mean glucose concentrations } \\
\text { (range mmol/l) }\end{array}$ & $\% C V$ \\
\hline October & 4 & $8 \cdot 2(7 \cdot 4-9 \cdot 3)$ & $9 \cdot 8$ \\
November & 7 & $5 \cdot 5(4 \cdot 6-6 \cdot 2)$ & $7 \cdot 6$ \\
December & 5 & $1 \cdot 3(1 \cdot 2-1 \cdot 5)$ & $9 \cdot 4$ \\
January & 9 & $23 \cdot 8(22 \cdot 0-26 \cdot 4)$ & $7 \cdot 4$ \\
February & 8 & $26 \cdot 4(21 \cdot 8-27 \cdot 7)$ & $7 \cdot 7$ \\
March & 8 & $19 \cdot 0(18 \cdot 0-20 \cdot 0)$ & $3 \cdot 4$ \\
April & 8 & $5 \cdot 6(1 \cdot 5-2 \cdot 2)$ & $11 \cdot 6$ \\
May & 8 & $15 \cdot 3(14 \cdot 2-6)$ & $11 \cdot 3$ \\
June & 8 & $20 \cdot 9(16 \cdot 2-27 \cdot 5)$ & $5 \cdot 5$ \\
July & 12 & $3 \cdot 7(3 \cdot 1-4 \cdot 2)$ & $17 \cdot 1$ \\
August & 11 & $12 \cdot 1(10 \cdot 2-13 \cdot 7)$ & $9 \cdot 6$ \\
September & 10 & & $7 \cdot 8$ \\
\hline
\end{tabular}

ranged from 3.9 to $7.3 \%$, while for the low control the range was 6.4 to $14 \%$. Four of the sites had not kept complete records of their internal quality control results. Over the 12 months since the introduction of the scheme imprecision has varied from $3 \cdot 4 \%$ to $17 \cdot 1 \%$ (table).

Performance over 12 months was also assessed by setting target limits of $\pm 10 \%$ and $\pm 20 \%$ of the mean value obtained by the laboratory (figure).

\section{Discussion}

The scheme is a success in that all blood glucose meter users that we contacted in our unit take part in a laboratory supervised quality assurance scheme. All users seemed happy with the scheme and many say that for them the main benefit was the increased confidence they have in their results. Users were aware of their legal responsibilities and felt more secure taking part in a quality control scheme in which performance requirements have been identified. Several authors have defined performance criteria for glucose meters. Skendzel et $a l^{6}$ suggested that a $\mathrm{CV}$ of $10 \%$ at a glucose concentration of $5 \mathrm{mmol} / 1$ was adequate while Price et al $^{7}$ suggested that a CV of $5 \%$ was necessary. The precision required depends on the clinical setting because certain situations have more stringent requirements than others. ${ }^{8}$ We feel that a $\mathrm{CV}$ of $10 \%$ is acceptable for our purposes. Of the eight users who consistently kept internal quality control records this criterion was met by all at the high level but only $38 \%$ of users

Glucose meter results compared with the laboratory target value. The $\pm 10 \%$ and $\pm 20 \%$ limits of acceptability are shown. at the low level. Those sites who have not kept their recording of internal quality control results up to date (four out of 12) have been asked to do so and have complied intermittently. There is a case for removing laboratory support from these sites if they fail to keep proper records and this will have to be considered in the future. There is no easy way to ensure that only "trained" staff use the meters as the meters are accessible in the wards. With education, further training courses, and good relations with the laboratory, however, we believe that this will occur. We also believe that the local laboratory must encourage adherence to the guidelines on good practice in order for them to be effective, because understanding of good analytical practice on the wards is negligible. The use of internal and external quality control results has resulted in several calls to the laboratory for help and has identified problems with meters.

The performance of participants in the external quality assessment scheme did not show an improvement over the 12 months following the introduction of the scheme. The greatest variation occurred outside the range 3-20 mmol/1 with $30 \%$ of users failing to achieve $\pm 20 \%$ target limits. As a result of our experience we recommend that users check meter readings outside the range $3-20 \mathrm{mmol} / 1$ by sending venous samples to the laboratory for glucose estimation. We also recommend that venous samples should be sent at intervals to the laboratory to check against meter results, as the quality assessment scheme does not check procedures such as taking the sample or its application to the strip. In practice we have found that apart from the monitoring of known diabetic patients, samples are usually both measured on the meter and sent to the laboratory, thus duplicating results. The wards often act on the meter result but use the laboratory result for confirmation. We hope to reduce this practice by improving confidence in the meters through continuing laboratory support.

1 Pharmacy Practice Research Group. Health screening for health promotion. Belfast. The School of Pharmacy. The health promotion. Belfast. The Scho

2 Department of Health. HN (Hazard) (87) 13 1987. Blood glucose measurements. Reliability of results produced in extra-laboratory areas. London: DHSS, 1987

3 Canadian Association of Pathologists. Guidelines on the use of blood glucose meters and non-meter blood glucose reagent strips in hospitals. Can Med Assoc J 1988;138: $27-9$.

4 ACB Joint Working Group on Quality Assurance. Control of clinical laboratory tests performed outside laboratories by non-laboratory staff Association of Clinical Biochemists Newsheet 1989;315:16-7.

5 Begley JP, Forrest ARW. Laboratory assessment of three reflectance meters designed for self monitoring of blood glucose concentrations. J Clin Pathol 1988;41:397-402.

6 Skendzel LP, Barnett RN, Platt R. Medically useful criteria for analytic performance of laboratory tests. $\mathrm{Am} \mathrm{J} \mathrm{Clin}$ for analytic performan

7 Price CP, Burrin JM, Natrass M. Extra-laboratory blood glucose measurement: a policy statement. Diabet Med glucose meas

8 Broughton PGM, Buckley BM. Performance requirements of tests performed nearer the patient. Scand J Clin Lab of tests performed near
Invest 1987;47:99-104. 